\title{
The number of circulating CD34-positive cells is an independent predictor of coronary artery calcification progression: Sub-analysis of a prospective multicenter study
}

\author{
Keishi Ichikawa ${ }^{1}$,, Toru Miyoshi ${ }^{1}$, Kazuhiro Osawa ${ }^{2}$, Takashi Miki ${ }^{1}$, \\ Kunihisa Kohno ${ }^{1}$, Kazufumi Nakamura ${ }^{1}$, Yasushi Koyama ${ }^{3}$, Hiroshi Ito ${ }^{1}$ \\ ${ }^{1}$ Department of Cardiovascular Medicine, Okayama University Graduate School of Medicine, \\ Density and Pharmaceutical Sciences, Okayama, Japan \\ ${ }^{2}$ Department of Cardiovascular Medicine, Japanese Red Cross Okayama Hospital, Okayama, Japan \\ ${ }^{3}$ Department of Cardiology, Sakurabashi Watanabe Hospital, Osaka, Japan
}

\begin{abstract}
Background: Decreases in circulating CD34-positive cells are associated with increases in cardiovascular events. We investigated the association between the number of CD34-positive cells and the progression of coronary artery calcification (CAC), a marker of atherosclerosis, in patients with hypercholesteremia under statin therapy in a sub-analysis of a multicenter study.

Methods: In the principal study, patients with CAC scores of 1-999 were treated with pitavastatin. Measurement of CAC by non-enhanced computed tomography and a blood test were performed at baseline and at 1-year follow-up. Patients were divided into two groups: CAC progression (change in CAC score $>0$ ) and non-progression. The number of circulating CD34-positive cells was counted using flow cytometry.

Results: A total of 156 patients (mean age 67 years, 55\% men) were included in this sub-analysis. CD34 positive cell numbers at baseline as a continuous variable was inversely correlated with annual change in the log-transformed CAC score $(r=-0.19, p=0.02)$. When patients were divided into high and low CD34 groups based on the median value of $0.8 \mathrm{cells} / \mu L$, the adjusted change in CAC score in the low-CD34 group was significantly greater than that in the high-CD34 group $(54.2 \%$ vs. $20.8 \%$, respectively, $p=0.04$ ). In multiple logistic analysis, a low CD34-positive cell number was an independent predictor of CAC progression, with an odds ratio of 2.88 (95\% confidence interval $1.28-6.49, p=0.01$ ). Conclusions: Low numbers of CD34-positive cells are associated with CAC progression in patients with hypercholesterolemia under statin therapy. The number of CD34-positive cells may help to identify patients at increased cardiovascular risk. (Cardiol J 2022; 29, 3: 423-431)
\end{abstract}

Key words: coronary artery calcification, computed tomography, endothelial progenitor cells, hypercholesterolemia

Address for correspondence: Toru Miyoshi, MD, PhD, Department of Cardiovascular Medicine, Okayama University, 2-5-1 Shikata-cho, Kita-ku, Okayama 700-8558, Japan, tel: +81-86-235-7351, fax: +81-86-235-7353,

e-mail: miyoshit@cc.okayama-u.ac.jp

Received: 30.10.2020 Accepted: 24.10.2021 Early publication date: 15.11.2021

This article is available in open access under Creative Common Attribution-Non-Commercial-No Derivatives 4.0 International (CC BY-NC-ND 4.0) license, allowing to download articles and share them with others as long as they credit the authors and the publisher, but without permission to change them in any way or use them commercially. 


\section{Introduction}

Endothelial progenitor cells are mononuclear cells largely derived from bone marrow. They can be quantified in peripheral blood using flow cytometry. CD34-positive mononuclear cells have the potential to differentiate into several lineages and contribute to vascular repair and regeneration $[1,2]$. Low counts of CD34-positive cells indicate reduced endothelial repair activity, with previous studies demonstrating a direct correlation between endothelial progenitor cell numbers and endothelial dysfunction [2]. Moreover, a previous report has demonstrated that a decrease in circulating progenitor cells is a predictor of cardiovascular events [3]. However, the mechanism underlying the association between CD34-positive cells and cardiovascular events has not been fully elucidated.

The coronary artery calcification (CAC) score determined by non-enhanced computed tomography (CT) reflects the presence and extent of coronary atherosclerosis and predicts future cardiovascular events in multiple populations $[4,5]$. A previous study has shown the association between CAC progression and adverse cardiovascular outcomes [6]. We have previously reported the results of a prospective multicenter study that examined the effects of intensive and standard pitavastatin treatment with or without eicosapentaenoic acid on the progression of CAC [7]. The study found that the progression of CAC in each patient group was not affected by any of the treatments. Therefore, it is of interest to find other factors involved in CAC progression.

In this study, we investigated the association between baseline circulating CD34-positive cell number and CAC progression in patients with hypercholesterolemia undergoing statin therapy.

\section{Methods}

\section{Study design}

This study was designed as a sub-analysis of a prospective, multicenter, randomized trial [7]. The main trial was conducted at 27 centers from May 2010 to August 2011. The design and results of the main study have already been published [7]. Briefly, the trial investigated the effects of intensive and standard statin therapy with or without eicosapentaenoic acid on the progression of CAC score over 1 year. After taking $2 \mathrm{mg} /$ day pitavastatin for 2 months to check for tolerance, all participants were randomly allocated to the $2 \mathrm{mg} /$ day pitavastatin (PIT2), $4 \mathrm{mg} /$ day pitavastatin (PIT4), or $2 \mathrm{mg} /$ day pitavastatin $+1800 \mathrm{mg} /$ day eicosapentaenoic acid (PIT2 + EPA) groups. Baseline blood test data and non-enhanced cardiac CT images were obtained immediately before starting the allocated treatment and repeated at 1-year follow-up. The data presented in this manuscript are a sub-analysis of the collected data. This study was conducted according to the principles of the Declaration of Helsinki and approved by the ethics committees of Okayama University Graduate School of Medicine, Dentistry, and Pharmaceutical Sciences and other hospitals. The main study is registered at UMIN Clinical Trial Registry (UMIN000003171). All study participants gave written informed consent.

\section{Study population}

Eligible participants were patients $>20$ years old, with an Agatston score of 1-999, hypercholesterolemia, and no history of cardiovascular disease. We excluded patients with a history of coronary revascularization (including percutaneous coronary intervention and coronary artery bypass surgery), Agatston score 0 or $>1000$, familial hypercholesterolemia, use of cyclosporine, and use of lipid-lowering agents excluding statins. A flow diagram of the study is shown in Figure 1. Among the 157 patients analyzed in the principal study, 1 patient was excluded because there were no data for CD34-positive cell number. Thus, 156 patients were included in this sub-analysis.

\section{CAC analysis and definition of CAC progression}

Non-enhanced CT imaging was performed at baseline and 1-year follow-up in a standardized fashion as previously described [7]. CT images were documented in a Digital Imaging and Communications in Medicine format, which was sent to the core laboratory at L\&L Company (Osaka, Japan) for blinded analysis. CAC score was calculated using the Agatston method [8]. To minimize the effect of interscan variability [9], two definitions of CAC progression were used; the percentage changes in CAC score $>0 \%$ and $>20 \%$ were applied in the analyses. The percentage change in CAC score was calculated as (CAC [follow up] - CAC [baseline]) / / CAC [baseline] $) \times 100$.

\section{Measurement of circulating \\ CD34-positive cells}

Peripheral blood was collected and incubated with fluorochrome-labeled monoclonal anti-human mouse antibodies to identify surface markers expressed on mononuclear cells. The number of 


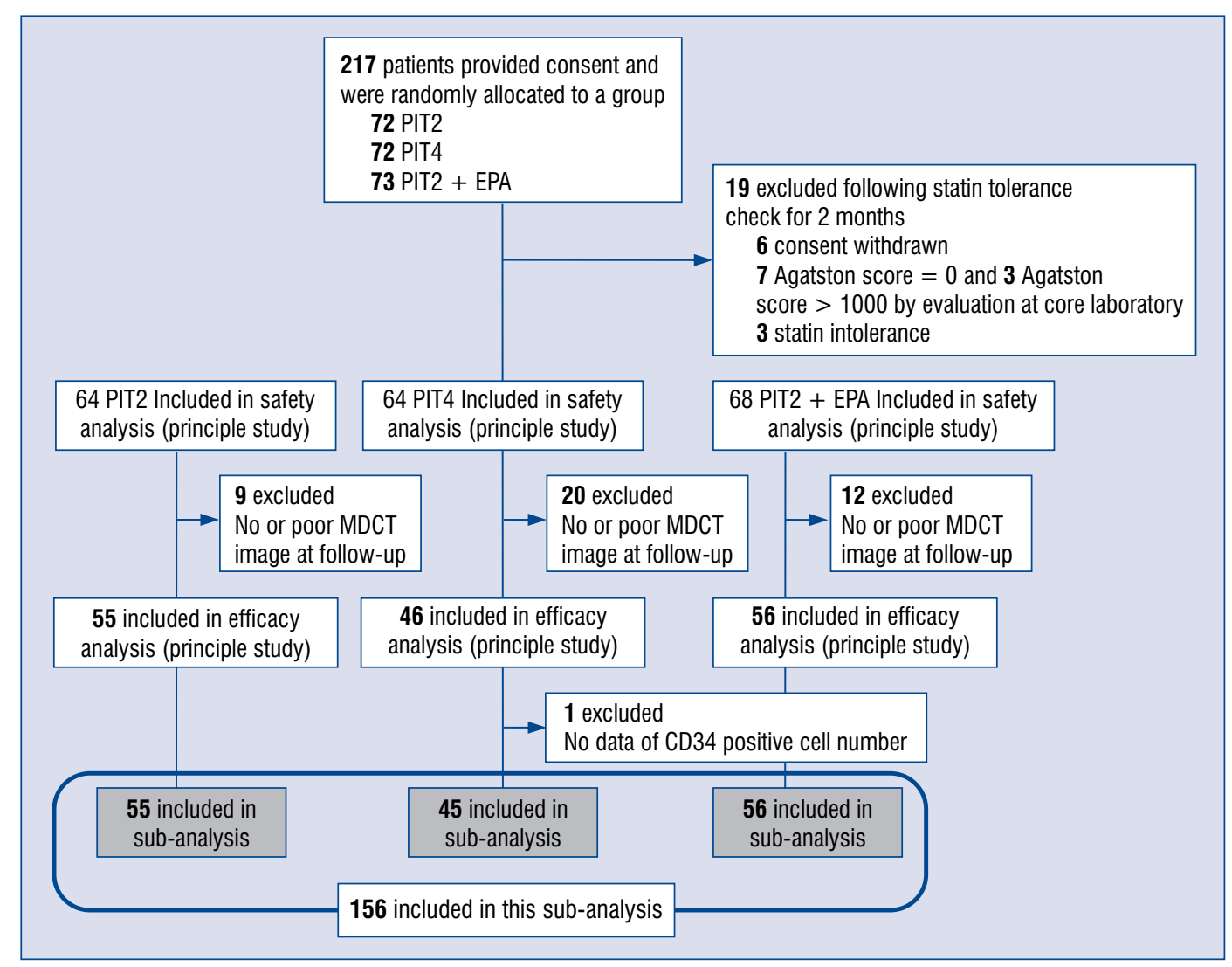

Figure 1. Flowchart showing enrollment of patients in the study. PIT2 $-2 \mathrm{mg} /$ day pitavastatin; PIT4 $-4 \mathrm{mg} / \mathrm{day}$ pitavastatin; EPA - $1800 \mathrm{mg} /$ day eicosapentaenoic acid; MDCT — multidetector row computed tomography.

circulating CD34-positive cells was counted by flow cytometry at an independent central study laboratory (SRL, Tokyo, Japan). The membrane expression of CD34 was studied in the lymphomonocyte gate. Results are expressed as the number of CD34-positive cells per $\mu \mathrm{L}$ blood, taking into account the number of leukocytes of each subject.

\section{Statistical analysis}

Continuous variables are presented as mean \pm standard deviation or median (interquartile range), as appropriate. Patients were classified into two groups based on median values of circulating CD34-positive cells, with a cut-off value of 0.8 cells $/ \mu \mathrm{L}$. Differences in continuous variables between the two groups were analyzed by Student's t-test or Mann-Whitney U-test, as appropriate. Categorical variables are presented as frequency and proportion $(\%)$, and were compared by $\chi^{2}$ analysis. In subsequent analysis, triglyceride, high-sensitivity $\mathrm{C}$-reactive protein (hsCRP), and CAC score were log transformed because they did not exhibit a normal distribution. Associations of variables were assessed by Pearson's correlation analysis. The annual change in log-transformed CAC score was calculated as follows: log transformed (CAC score at follow-up) - log transformed (CAC score at baseline). The mean change in CAC score and 95\% confidence intervals (CI) adjusted for age, gender, and smoking status were estimated using multivariate linear models. Univariate logistic regression analysis was performed to identify potential predictive factors for CAC progression. Multivariate logistic regression analysis was performed using the variables with $\mathrm{p}$-value $<0.05$ in the univariate analysis. All statistical tests were two-sided, and p-value $<0.05$ was considered significant. All statistical analyses were performed using SPSS 27.0 for Windows (IBM, Armonk, NY, USA).

\section{Results}

In total, 156 patients were enrolled in this study sub-analysis. The baseline patient characteristics are shown in Table 1 . The mean age was 67 years, and $55 \%$ of patients were men. $82 \%$ of patients had hypertension and $27 \%$ had diabetes mellitus. The median (interquartile rage) $\mathrm{CAC}$ 
Table 1. Baseline patient characteristics.

\begin{tabular}{lc}
\hline Variables & $\mathbf{N}=156$ \\
\hline Age [years] & $67 \pm 9$ \\
Male gender & $85(55)$ \\
Body mass index $\left[\mathrm{kg} / \mathrm{m}^{2}\right]$ & $25.1 \pm 4.0$ \\
Hypertension & $127(81)$ \\
Diabetes mellitus & $42(27)$ \\
Current smoker & $26(17)$ \\
Warfarin use & $7(4)$ \\
Creatinine [mg/dL] & $0.87 \pm 1.01$ \\
AST [IU/L] & $27 \pm 13$ \\
ALT [IU/L] & $28 \pm 22$ \\
Total cholesterol [mg/dL] & $175 \pm 31$ \\
LDL-C [mg/dL] & $93 \pm 24$ \\
HDL-C [mg/dL] & $55 \pm 14$ \\
Triglyceride [mg/dL] & $115(89-163)$ \\
HbA1c [\%] & $5.7 \pm 0.7$ \\
hsCRP [mg/L] & $537(327-1058)$ \\
CAC score & $97(26-237)$ \\
PIT2/PIT4/PIT2 + EPA & $55(35) / 45(29) / 56(36)$ \\
CD34-positive cell number $[/ \mu L]$ & $1.0 \pm 0.7$ \\
\hline
\end{tabular}

Data are presented as mean \pm standard deviation, number (\%), or median (interquartile range). AST - aspartate aminotransferase; ALT - alanine aminotransferase; LDL-C — low-density lipoprotein cholesterol; HDL-C - high-density lipoprotein cholesterol; HbA1c - glycated hemoglobin A1c; hsCRP - high-sensitivity C-reactive protein; CAC score - coronary artery calcium score; PIT2 - $2 \mathrm{mg} /$ /day pitavastatin; PIT4 - $4 \mathrm{mg} /$ day pitavastatin; EPA $-1800 \mathrm{mg} /$ /day eicosapentaenoic acid

score was 97 (26-237) and the mean (standard deviation) serum CD34-positive cell number was $1.0(0.7) \mathrm{cells} / \mu \mathrm{L}$.

Simple correlation coefficients for the association between CD34-positive cell number and other variables are shown in Table 2 . The baseline number of CD34-positive cells was significantly positively associated with male gender $(\mathrm{r}=0.38$, $\mathrm{p}<0.01)$ and smoking status $(\mathrm{r}=0.30, \mathrm{p}<0.01)$, and was significantly inversely associated with age $(\mathrm{r}=-0.26, \mathrm{p}<0.01)$. Meanwhile, there were no significant correlations between the baseline number of CD34-positive cells and CAC score.

Next, we evaluated the association between the baseline number of CD34-positive cells and the annual change in CAC score. At 1-year follow-up, 117 (75\%) patients had an increase in CAC score compared with baseline. The percentage change in CAC score in all patients was $36.6 \%$. There was no significant difference in percentage change in CAC score between the PIT2, PIT4, and PIT1 + EPA groups $(31.1 \%, 38.9 \%$, and $40.2 \%$, respectively, $\mathrm{p}=0.86$ ). Table 3 presents the results of the simple correlation analysis showing
Table 2. Correlations between number of CD34-positive cells and other variables.

\begin{tabular}{lcc}
\hline Variables & $\mathbf{r}$ & $\mathbf{p}$ \\
\hline Age & -0.26 & $<0.01$ \\
Male gender & 0.38 & $<0.01$ \\
Hypertension & -0.02 & 0.81 \\
Diabetes mellitus & 0.12 & 0.14 \\
Smoker & 0.30 & $<0.01$ \\
Warfarin use & -0.01 & 0.90 \\
Creatinine & -0.03 & 0.68 \\
Total cholesterol & 0.05 & 0.57 \\
LDL-C & 0.16 & 0.05 \\
HDL-C & -0.14 & 0.09 \\
Triglyceride & 0.09 & 0.27 \\
hsCRP* & 0.13 & 0.12 \\
CAC score $^{*}$ & -0.06 & 0.43 \\
\hline
\end{tabular}

*Triglyceride, hsCRP, and CAC score were log-transformed in this analysis. LDL-C - low-density lipoprotein cholesterol; HDL-C high-density lipoprotein cholesterol; hsCRP — high-sensitivity C-reactive protein; CAC score - coronary artery calcium score

Table 3. Correlations between annual change in coronary artery calcium (CAC) score and other variables

\begin{tabular}{lcc}
\hline Variables & $\mathbf{r}$ & $\mathbf{p}$ \\
\hline Age & 0.02 & 0.80 \\
Male gender & 0.05 & 0.57 \\
Hypertension & -0.08 & 0.33 \\
Diabetes & 0.02 & 0.78 \\
Smoker & -0.11 & 0.19 \\
Warfarin use & -0.06 & 0.47 \\
Creatinine & 0.13 & 0.12 \\
Total cholesterol & -0.07 & 0.40 \\
LDL-C & -0.15 & 0.07 \\
HDL-C & 0.02 & 0.78 \\
Triglyceride* & 0.08 & 0.34 \\
hsCRP* & -0.03 & 0.67 \\
CD34 positive cell number & -0.19 & 0.02 \\
\hline
\end{tabular}

*Triglyceride and hsCRP were log-transformed in this analysis. LDL-C - low-density lipoprotein cholesterol; HDL-C — high-density lipoprotein cholesterol; hsCRP — high-sensitivity C-reactive protein

the association between change in CAC score and baseline variables. Age, sex, low-density lipoprotein cholesterol (LDL-C), high-density lipoprotein cholesterol (HDL-C), triglyceride, and hsCRP at baseline were not significantly correlated with annual change in log-transformed CAC score. Meanwhile, CD34-positive cell numbers at baseline as a continuous 
Table 4. Comparison of baseline characteristics between the high- and low-CD34 groups.

\begin{tabular}{lccc}
\hline & High-CD34 group & Low-CD34 group & P \\
\hline $\mathrm{N}$ & 82 & 74 & \\
Age [years] & $65 \pm 10$ & $69 \pm 9$ & $<0.01$ \\
Male gender & $60(73)$ & $25(34)$ & $<0.01$ \\
Body mass index $\left[\mathrm{kg} / \mathrm{m}^{2}\right]$ & $25.6 \pm 4.1$ & $24.6 \pm 3.8$ & 0.13 \\
Hypertension & $65(79)$ & $62(84)$ & 0.47 \\
Diabetes mellitus & $23(28)$ & $19(26)$ & 0.74 \\
Current smoker & $21(26)$ & $5(7)$ & $<0.01$ \\
Warfarin use & $5(6)$ & $2(3)$ & 0.45 \\
Creatinine [mg/dL] & $0.81 \pm 0.22$ & $0.93 \pm 1.45$ & 0.47 \\
AST [IU/L] & $28 \pm 14$ & $26 \pm 13$ & 0.50 \\
ALT [IU/L] & $31 \pm 21$ & $25 \pm 22$ & 0.11 \\
Total cholesterol [mg/dL] & $177 \pm 30$ & $174 \pm 33$ & 0.59 \\
LDL-C [mg/dL] & $96 \pm 23$ & $90 \pm 25$ & 0.16 \\
HDL-C [mg/dL] & $54 \pm 12$ & $57 \pm 15$ & 0.17 \\
Triglyceride [mg/dL] & $123(95-167)$ & $106(77-155)$ & 0.06 \\
HbA1c [\%] & $5.8 \pm 0.9$ & $5.7 \pm 0.5$ & 0.62 \\
hsCRP [mg/L] & $545(338-1110)$ & $530(305-945)$ & 0.71 \\
CAC score & $90(24-242)$ & $101(33-225)$ & 0.74 \\
PIT2/PIT4/PIT2 + EPA & $29(35) / 24(29) / 29(35)$ & $26(35) / 21(28) / 27(37)$ & 0.99 \\
CD34-positive cell number $[/ \mu L]$ & $1.5 \pm 0.6$ & $0.5 \pm 0.2$ & $<0.01$ \\
\hline
\end{tabular}

Data are presented as mean \pm standard deviation, number (\%), or median (interquartile range). AST — aspartate aminotransferase; ALT — alanine aminotransferase; LDL-C — low-density lipoprotein cholesterol; HDL-C — high-density lipoprotein cholesterol; HbA1c - glycated hemoglobin A1c; hsCRP - high-sensitivity C-reactive protein; CAC score - coronary artery calcium score; PIT2 - 2 mg/day pitavastatin; PIT4 $-4 \mathrm{mg} /$ day pitavastatin; EPA $-1800 \mathrm{mg} /$ day eicosapentaenoic acid

variable was inversely correlated with annual change in log-transformed CAC score $(r=-0.19, \mathrm{p}=0.02)$.

Furthermore, patients were classified into two groups based on the median number of circulating CD34-positive cells $(0.8$ cells $/ \mu \mathrm{L})$ and defined as highand low-CD34 groups. Baseline characteristics were compared between the high-CD34 and low-CD34 patients (Table 4). The low-CD34 group was older and had a lower prevalence of smokers and male patients compared with the high-CD34 group. No significant differences were observed between the two groups in any of the blood test variables. In addition, baseline $\mathrm{CAC}$ score was not significantly different between the two groups. The change in CAC score was compared between the high- and low-CD34 groups after adjusting for age, gender, and smoking status, which were significantly different between the two groups. The adjusted change in CAC score in the low-CD34 group was significantly greater than that in the high-CD34 group (53.9\% [95\% CI 31.3-76.5] vs. $21.1 \%$ [95\% CI $-0.3-42.5]$, respectively, $p=0.04$; Fig. 2 ).

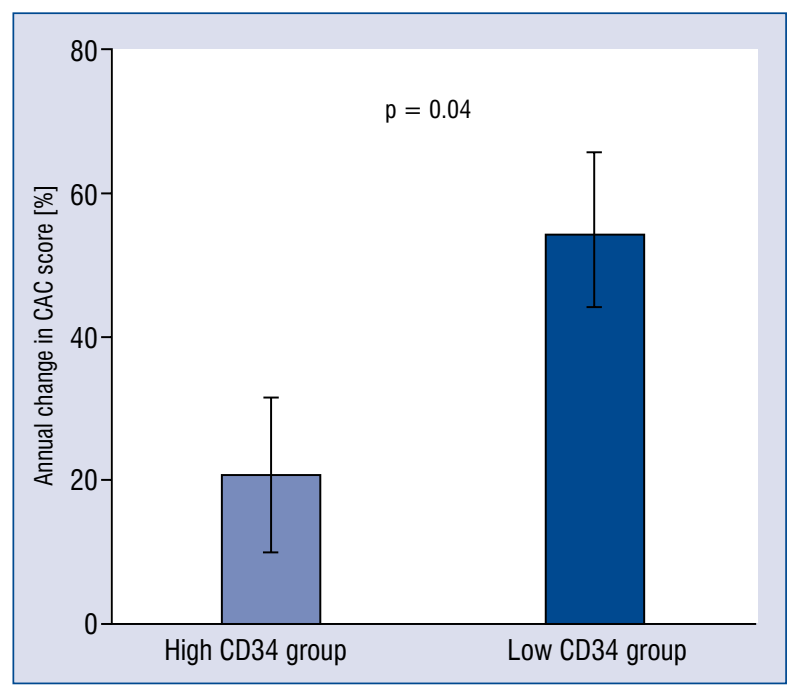

Figure 2. Comparison of the adjusted percentage change in coronary artery calcium (CAC) score between high- and low-CD34 groups. CAC scores were adjusted for age and gender. Bars represent mean $\pm 95 \%$ confidential interval. 
Table 5. Univariate and multivariate predictors of coronary artery calcium (CAC) progression.

\begin{tabular}{|c|c|c|c|c|c|c|}
\hline \multirow[t]{2}{*}{ Variables } & \multicolumn{3}{|c|}{ Univariable } & \multicolumn{3}{|c|}{ Multivariable } \\
\hline & Odds ratio & $95 \% \mathrm{Cl}$ & $\mathbf{P}$ & Odds ratio & $95 \% \mathrm{Cl}$ & $\mathbf{P}$ \\
\hline Age ( $\geq 65$ years) & 1.08 & $0.50-2.34$ & 0.84 & & & \\
\hline Male gender & 1.04 & $0.50-2.14$ & 0.93 & & & \\
\hline Hypertension & 0.95 & $0.37-2.42$ & 0.91 & & & \\
\hline Diabetes mellitus & 1.59 & $0.66-3.80$ & 0.30 & & & \\
\hline Current smoker & 0.71 & $0.279-1.777$ & 0.46 & & & \\
\hline Warfarin use & 0.43 & 0.09-1.99 & 0.28 & & & \\
\hline Creatinine & 1.17 & $0.56-2.34$ & 0.66 & & & \\
\hline LDL-C & 0.98 & $0.97-1.00$ & 0.02 & 0.99 & $0.97-1.00$ & 0.08 \\
\hline HDL-C & 1.01 & $0.98-1.04$ & 0.47 & & & \\
\hline $\mathrm{HbA1c}$ & 1.17 & $0.63-2.16$ & 0.63 & & & \\
\hline CAC score* & 1.95 & $1.15-3.23$ & 0.01 & 1.82 & $1.05-3.17$ & 0.03 \\
\hline Low CD34 group & 2.97 & $1.35-6.52$ & $<0.01$ & 2.88 & $1.28-6.49$ & 0.01 \\
\hline PIT2 & 0.63 & $0.39-1.76$ & 0.83 & & & \\
\hline PIT4 & 1.24 & $0.55-2.81$ & 0.61 & & & \\
\hline PIT2 + EPA & 1.00 & $0.47-2.13$ & 1.00 & & & \\
\hline
\end{tabular}

${ }^{*}$ CAC score was log-transformed in this analysis. $\mathrm{Cl}$ — confidence interval; LDL-C — low-density lipoprotein cholesterol; HDL-C — high-density lipoprotein cholesterol; HbA1c - glycated hemoglobin A1c; PIT2 - $2 \mathrm{mg} /$ day pitavastatin; PIT4 $-4 \mathrm{mg} /$ day pitavastatin; EPA — $1800 \mathrm{mg} /$ day eicosapentaenoic acid

Table 5 shows the unadjusted and adjusted odds ratio (OR) for the association between clinical variables and CAC progression. In univariate logistic regression analysis, low CD34-positive cell numbers $(<0.8$ cells $/ \mu \mathrm{L})$, high CAC score, and high LDL-C were significantly associated with $\mathrm{CAC}$ progression. In multivariate logistic regression analysis, low CD34-positive cell numbers and high $\mathrm{CAC}$ score remained independent predictors of CAC progression, with ORs of 2.88 (95\% CI: $1.28-6.49, \mathrm{p}=0.01)$ and 1.82 (95\% CI: $1.05-3.17$, $\mathrm{p}=0.03)$, respectively. To validate the association between number of CD34-positive cells and CAC progression further, CAC progression was redefined as a change in CAC score $>20 \%$. In line with previous analysis, univariate logistic regression analysis showed that low CD34-positive cell number was a significant independent predictor of percentage change in CAC score $>20 \%$ with an OR of 1.96 (95\% CI: $1.04-3.70, \mathrm{p}=0.04)$.

Finally, the association between annual change in CD34-positive cells and CAC progression was analyzed. At 1-year follow-up, 85 (54.5\%) patients had an increase in CD34-positive cell numbers compared with baseline. The percentage change in the number of CD34-positive cells in all patients was $27.3 \%$. There was no significant difference in the percentage change in CD34-positive cell numbers between the PIT2, PIT4, and PIT1 + EPA groups $(39.1 \%, 23.7 \%$, and $19.0 \%$, respectively, $\mathrm{p}=0.40$ ). Meanwhile, at 1-year follow-up, $117(75 \%)$ patients had an increase in CAC score compared with baseline. The percentage change in CAC score in all patients was $36.6 \%$. There was also no significant difference in the percentage change in CAC score between the PIT2, PIT4, and PIT1 + EPA groups $(31.1 \%, 38.9 \%$, and $40.2 \%$, respectively, $\mathrm{p}=0.86)$. No significant association between the change in CD34-positive cell numbers and the change in CAC score was observed when all patients were combined $(\mathrm{r}=0.10, \mathrm{p}=0.24)$.

\section{Discussion}

The major finding of the present study is that low numbers of circulating CD34-positive cells are independently associated with CAC progression in patients with hypercholesterolemia under statin therapy. To the best of our knowledge, this is the first study to investigate the association between the number of CD34-positive cells and CAC progression. Our finding further characterizes the association between low CD34-positive cell numbers and the development of cardiovascular events. The measurement of circulating CD34-positive 
cells may help identify patients at higher risk of atherosclerotic disease.

Endothelial progenitor cells that express CD34 on their cell surface play an important role in maintaining and repairing the vascular endothelium [10]. A decrease in the number of CD34-positive cells suggests a reduction in endothelial repair activity, which may result in insufficient repair. Previous studies have confirmed a direct correlation between endothelial progenitor cell numbers and endothelial dysfunction, measured as brachial artery flow-mediated dilation [2]. Moreover, a report has demonstrated that reduced baseline CD34-positive cell numbers is a predictor of mortality among patients with coronary artery disease risk factors [11-13]. Although CD34-positive cell numbers are reduced by conventional cardiovascular risk factors [14-16], the direct contribution of CD34-positive cells to cardiovascular events remains unclear. Our result may simply denote that patients with low CD34-positive cell numbers have more cardiovascular risk factors than patients with high CD34-positive cell numbers. However, taken together with data from other groups, the measurement of CD34-positive cell numbers may be useful to evaluate the risk of cardiovascular disease.

The CAC score reflects the presence and extent of coronary atherosclerosis and is a useful tool for risk stratification of adverse events $[4,5]$. In a population-based study of 6722 participants, the CAC score was shown to predict cardiovascular events independently of traditional risk factors [17]. Meanwhile, statins lower the risk of cardiovascular events [18]. Considering the procalcific effects of statins on coronary arteries, there is a possibility that statins reduce the absolute risk of cardiovascular events in patients on statin therapy. A previous study - the Multi-Ethnic Study of Atherosclerosis - demonstrated that $\mathrm{CAC}>0$ was associated with a nearly twofold higher risk of incident cardiovascular events regardless of baseline statin or incident statin use [19]. CAC can therefore risk stratify individuals already taking statins. Moreover, serial CAC score assessment has also been proposed as a useful tool for monitoring disease progression, and $\mathrm{CAC}$ progression is an independent predictor for adverse cardiovascular outcomes [6]. In previous short-term and long-term studies, standard coronary risk factors have been related to CAC progression [20,21]. In this study, two definitions of CAC progression were used: annual percentage change in CAC score $>0 \%$ and $>20 \%$ were applied to exclude interscan variability, and confirmed independent association between number of CD34-positive cells and CAC progression.

Our study demonstrated the association between the baseline number of CD34-positive cells and CAC progression; however, whether CD34-positive cells are directly involved in CAC progression remains unclear for several reasons. First, CD34-positive cells as markers of endothelial dysfunction (the earliest sign of atherosclerosis) and CAC, which is found in advanced atherosclerotic lesions, reflect different stages of atherosclerosis $[2,22,23]$. Second, previous experimental studies have suggested that osteopontin-mediated vascular calcification may originate from osteoprogenitor cells and occurs in the adventitia independently of endothelial injury [24]. However, other studies of the relationship between endothelial dysfunction and CAC have shown conflicting results [25, 26]. Further study is needed to clarify the role of CD34-positive cells in vascular calcification.

Our study did not find a significant association between the change in CD34-positive cell number and $\mathrm{CAC}$ progression. One explanation could be the effect of statins and eicosapentaenoic acid on these measures. Previous studies have demonstrated that both statin monotherapy and statin plus omega-3 fatty acids increase CD34-positive cell numbers $[27,28]$. Additionally, intensive lipid-lowering by statins has been reported to increase CAC $[29,30]$. Thus, the increase in both CD34-positive cells and CAC by statins could affect the association between the change in CD34-positive cells and CAC progression. Another explanation is that the follow-up duration of this study was too short to assess the association between them. A long-term follow-up may be needed to clarify the association between the change in CD34-positive cell numbers and CAC progression.

\section{Limitations of the study}

Our study has some limitations that should be addressed. First, our study includes only Japanese patients with hypercholesterolemia. The prevalence and development of CAC score have significant differences by race or ethnicity [31]. In addition, patients with hypercholesterolemia are known to exhibit lower numbers of CD34-positive cells than the general population [10]. Therefore, our result may not reflect the general population and other ethnic groups. Second, all patients enrolled in our study were taking statin therapies. CAC progression might be affected by statin use due to its procalcific effects [32]. Third, we defined CAC progression as an endpoint in this study, not 
cardiovascular events. The prognostic significance of our study should be confirmed in larger studies with long follow-up periods.

\section{Conclusions}

In conclusion, our study demonstrates the association between low CD34-positive cell numbers and CAC progression in patients with hypercholesterolemia, which may explain the association between the number of CD34-positive cells and cardiovascular events. The quantification of circulating CD34-positive cells may help identify patients at higher risk of atherosclerotic disease.

\section{Acknowledgments}

This research was funded by the Japan Heart Foundation (No. 12090021).

We thank Hirohiko Asonuma, MD, Satoru Sakuragi, MD, Makoto Nakahama, MD, Yusuke Kawai, MD, Tadahisa Uesugi, MD, Takefumi Oka, MD, Mitsuru Munemasa, MD, Natsuki Takahashi, MD, Naoki Mukohara, MD, Seiji Habara, MD, Yusuke Katayama, MD, Ritsuko Terasaka, MD, Atsushi Mima, MD, Hitoshi Matsubara, MD, Shingo Hosogi, MD, Masayuki Doi, MD, Masayuki Ueeda, MD, Norio Urabe, MD, Kazufumi Takeuchi, MD, Yasuharu Namba, MD, Tetsuya Sato, MD, Nobuyuki Yamada, MD, Masahito Taniguchi, MD, Yutaka Kajikawa, MD, Kouki Watanabe, MD, Kenichi Hisamatsu, MD, Hiroo Kobayashi, MD, and Kiyoaki Maekawa, MD, who were the PEACH Investigators. We thank Kaoru Akazawa, Miyuki Fujiwara, and Masayo Ohmori for their technical assistance.

\section{Conflict of interest: None declared}

\section{References}

1. Asahara T, Murohara T, Sullivan A, et al. Isolation of putative progenitor endothelial cells for angiogenesis. Science. 1997; 275(5302): 964-967, doi: 10.1126/science.275.5302.964, indexed in Pubmed: 9020076.

2. Hill JM, Zalos G, Halcox JPJ, et al. Circulating endothelial progenitor cells, vascular function, and cardiovascular risk. N Engl J Med. 2003; 348(7): 593-600, doi: 10.1056/NEJMoa022287, indexed in Pubmed: 12584367.

3. Werner N, Kosiol S, Schiegl T, et al. Circulating endothelial progenitor cells and cardiovascular outcomes. N Engl J Med. 2005; 353(10): 999-1007, doi: 10.1056/NEJMoa043814, indexed in Pubmed: 16148285.

4. Wexler L, Brundage B, Crouse J, et al. Coronary artery calcification: pathophysiology, epidemiology, imaging methods, and clinical implications. A statement for health professionals from the American Heart Association. Writing Group. Circulation.
1996; 94(5): 1175-1192, doi: 10.1161/01.cir.94.5.1175, indexed in Pubmed: 8790070.

5. Greenland P, LaBree L, Azen SP, et al. Coronary artery calcium score combined with Framingham score for risk prediction in asymptomatic individuals. JAMA. 2004; 291(2): 210-215, doi: 10.1001/jama.291.2.210, indexed in Pubmed: 14722147.

6. Budoff MJ, Hokanson JE, Nasir K, et al. Progression of coronary artery calcium predicts all-cause mortality. JACC Cardiovasc Imaging. 2010; 3(12): 1229-1236, doi: 10.1016/j.jcmg.2010.08.018, indexed in Pubmed: 21163451.

7. Miyoshi T, Kohno K, Asonuma H, et al. Effect of intensive and standard pitavastatin treatment with or without eicosapentaenoic acid on progression of coronary artery calcification over 12 months: prospective multicenter study. Circ J. 2018; 82(2): 532-540, doi: 10.1253/circj.CJ-17-0419, indexed in Pubmed: 28867681.

8. Agatston AS, Janowitz WR, Hildner FJ, et al. Quantification of coronary artery calcium using ultrafast computed tomography. J Am Coll Cardiol. 1990; 15(4): 827-832, doi: 10.1016/07351097(90)90282-t, indexed in Pubmed: 2407762.

9. Hokanson JE, MacKenzie T, Kinney G, et al. Evaluating changes in coronary artery calcium: an analytic method that accounts for interscan variability. AJR Am J Roentgenol. 2004; 182(5): 1327-1332, doi: 10.2214/ajr.182.5.1821327, indexed in Pubmed: 15100140 .

10. Fadini GP, Losordo D, Dimmeler S. Critical reevaluation of endothelial progenitor cell phenotypes for therapeutic and diagnostic use. Circ Res. 2012; 110(4): 624-637, doi: 10.1161/CIRCRESAHA.111.243386, indexed in Pubmed: 22343557.

11. Fadini GP, de Kreutzenberg S, Agostini C, et al. Low CD34+ cell count and metabolic syndrome synergistically increase the risk of adverse outcomes. Atherosclerosis. 2009; 207(1): 213-219, doi: 10.1016/j.atherosclerosis.2009.03.040, indexed in Pubmed: 19406403.

12. Samman Tahhan A, Hammadah M, Raad M, et al. Progenitor cells and clinical outcomes in patients with acute coronary syndromes. Circ Res. 2018; 122(11): 1565-1575, doi: 10.1161/CIRCRESAHA.118.312821, indexed in Pubmed: 29514830.

13. Patel RS, Li Q, Ghasemzadeh N, et al. Circulating CD34+ progenitor cells and risk of mortality in a population with coronary artery disease. Circ Res. 2015; 116(2): 289-297, doi: 10.1161/ CIRCRESAHA.116.304187, indexed in Pubmed: 25323857.

14. Di Stefano R, Barsotti MC, Felice F, et al. Smoking and endothelial progenitor cells: a revision of literature. Curr Pharm Des. 2010; 16(23): 2559-2566, doi: 10.2174/138161210792062939, indexed in Pubmed: 20550506.

15. Umemura T, Soga J, Hidaka T, et al. Aging and hypertension are independent risk factors for reduced number of circulating endothelial progenitor cells. Am J Hypertens. 2008; 21(11): 1203-1209, doi: 10.1038/ajh.2008.278, indexed in Pubmed: 18787520.

16. Fadini GP, Miorin M, Facco M, et al. Circulating endothelial progenitor cells are reduced in peripheral vascular complications of type 2 diabetes mellitus. J Am Coll Cardiol. 2005; 45(9): 1449-1457, doi: 10.1016/j.jacc.2004.11.067, indexed in Pubmed: 15862417.

17. Detrano R, Guerci AD, Carr JJ, et al. Coronary calcium as a predictor of coronary events in four racial or ethnic groups. N Engl J Med. 2008; 358(13): 1336-1345, doi: 10.1056/NEJMoa072100, indexed in Pubmed: 18367736.

18. Kimura T, Iimuro S, Taguchi I, et al. High-dose versus low-dose pitavastatin in japanese patients with stable coronary artery 
disease (REAL-CAD): a randomized superiority trial. Circulation. 2018; 137(19): 1997-2009, doi: 10.1161/CIRCULATIONAHA.117.032615, indexed in Pubmed: 29735587.

19. Rifai MAl, Blaha MJ, Patel J, et al. Coronary artery calcification, statin use and long-term risk of atherosclerotic cardiovascular disease events (from the multi-ethnic study of atherosclerosis). Am J Cardiol. 2020; 125(6): 835-839, doi: 10.1016/j.amjcard.2019.12.031, indexed in Pubmed: 31980142.

20. Kronmal RA, McClelland RL, Detrano R, et al. Risk factors for the progression of coronary artery calcification in asymptomatic subjects: results from the Multi-Ethnic Study of Atherosclerosis (MESA). Circulation. 2007; 115(21): 2722-2730, doi: 10.1161/CIRCULATIONAHA.106.674143, indexed in Pubmed: 17502571.

21. Gassett AJ, Sheppard L, McClelland RL, et al. Risk factors for long-term coronary artery calcium progression in the multiethnic study of atherosclerosis. J Am Heart Assoc. 2015; 4(8): e001726, doi: 10.1161/JAHA.114.001726, indexed in Pubmed: 26251281.

22. Nakahara T, Dweck MR, Narula N, et al. Coronary Artery Calcification: From Mechanism to Molecular Imaging. JACC Cardiovasc Imaging. 2017; 10(5): 582-593, doi: 10.1016/j.jcmg.2017.03.005, indexed in Pubmed: 28473100.

23. Gutiérrez E, Flammer AJ, Lerman LO, et al. Endothelial dysfunction over the course of coronary artery disease. Eur Heart J. 2013; 34(41): 3175-3181, doi: 10.1093/eurheartj/eht351, indexed in Pubmed: 24014385.

24. Towler DA, Bidder M, Latifi T, et al. Diet-induced diabetes activates an osteogenic gene regulatory program in the aortas of low density lipoprotein receptor-deficient mice. J Biol Chem. 1998; 273(46): 30427-30434, doi: 10.1074/jbc.273.46.30427, indexed in Pubmed: 9804809.

25. Ramadan MM, Mahfouz EM, Gomaa GF, et al. Evaluation of coronary calcium score by multidetector computed tomography in relation to endothelial function and inflammatory markers in asymptomatic individuals. Circ J. 2008; 72(5): 778-785, doi: 10.1253/circj.72.778, indexed in Pubmed: 18441459.

26. Han SH, Gerber TC, Suwaidi JAl, et al. Relationship between coronary endothelial function and coronary calcification in early atherosclerosis. Atherosclerosis. 2010; 209(1): 197-200, doi: 10.1016/j.atherosclerosis.2009.08.027, indexed in Pubmed: 19962702.

27. Pirro M, Schillaci G, Romagno PF, et al. Influence of short-term rosuvastatin therapy on endothelial progenitor cells and endothelial function. J Cardiovasc Pharmacol Ther. 2009; 14(1): 14-21, doi: 10.1177/1074248408331021, indexed in Pubmed: 19158317.

28. Chantzichristos VG, Agouridis AP, Moutzouri E, et al. Effect of rosuvastatin or its combination with omega-3 fatty acids on circulating CD34(+) progenitor cells and on endothelial colony formation in patients with mixed dyslipidaemia. Atherosclerosis. 2016; 251: 240-247, doi: 10.1016/j.atherosclerosis.2016.06.047, indexed in Pubmed: 27415612.

29. Smit JM, van Rosendael AR, El Mahdiui M, et al. Impact of clinical characteristics and statins on coronary plaque progression by serial computed tomography angiography. Circ Cardiovasc Imaging. 2020; 13(3): e009750, doi: 10.1161/CIRCIMAGING.119.009750, indexed in Pubmed: 32160786.

30. Lee SE, Sung JiM, Andreini D, et al. Effects of statins on coronary atherosclerotic plaques: the PARADIGM study. JACC Cardiovasc Imaging. 2018; 11(10): 1475-1484, doi: 10.1016/j. jcmg.2018.04.015, indexed in Pubmed: 29909109.

31. Orimoloye OA, Budoff MJ, Dardari ZA, et al. Race/Ethnicity and the prognostic implications of coronary artery calcium for allcause and cardiovascular disease mortality: the coronary artery calcium consortium. J Am Heart Assoc. 2018; 7(20): e010471, doi: 10.1161/JAHA.118.010471, indexed in Pubmed: 30371271.

32. Puri R, Nicholls SJ, Shao M, et al. Impact of statins on serial coronary calcification during atheroma progression and regression. J Am Coll Cardiol. 2015; 65(13): 1273-1282, doi: 10.1016/j. jacc.2015.01.036, indexed in Pubmed: 25835438. 